\title{
New PHOX ligands monoterpene derivatives and their application in catalytic transfer hydrogenation of ketones
}

Anna Kmieciak, Marek Krzemiński ankakmieciak@gmail.com

Faculty of Chemistry, Nicolaus Copernicus University, Torun, Poland

\begin{abstract}
In this paper we present synthesis new PHOX ligands $a$ - and $\beta$-pinene derivatives. We applied their ruthenium (I) complexes in asymmetric catalytic transfer hydrogenation of ketones with good yields and enantioselectivity.
\end{abstract}

\section{Introduction}

The phosphine-oxazoline ligands (PHOX) have a wide range of applications in present-day asymmetric catalysis [1]. The PHOX was show by Pfaltz [2], Helmchen [3], Williams [4] in 1993. PHOX are an efficient, non- $\mathrm{C}_{2}$-symetric, $\mathrm{P}, \mathrm{N}$-chelating ligand class. Crabtree's catalyst $\left[(\mathrm{cod}) \operatorname{Ir}\left(\mathrm{PCy}_{3}\right)(\mathrm{py})\right]\left[\mathrm{PF}_{6}\right]$ [5] 1 became an inspiration to create new PHOX ligands. Crabtee's catalyst has high activity in catalytic hydrogenation of highly substituted olefins. PHOX ligands were utilized in numerous asymmetric reactions, which are catalyzed by transition metals, such as allylic alkylations [6], allylation reactions [7], Heck reactions [8], hydrogenations of olefins [9] and ketones [10], transfer hydrogenation of ketones [11], Diels-Alder reactions [12] and conjugate addition to enones [13]. Modifications of PHOX ligands 2 could be made at the carbon atom a to the oxazoline nitrogen and at the two aryl groups on phosphorus [11].
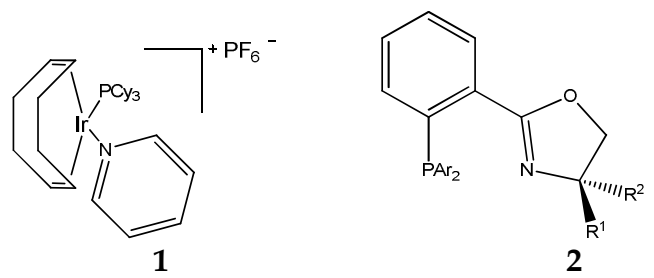

Fig. 1 Crabtree's catalyst (1) and PHOX ligands (2) \

\subsection{Synthesis method of PHOX ligands}

Synthesis of the PHOX ligands involves preparation of 2-(2-halogeno phenyl)oxazolines and then formation of the $\mathrm{P}$ derivatives by the substitution of halogen. The starting materials are amino alcohols derived usually from a-amino acids. In first step of PHOX ligands synthesis, amino alcohol is transformed into halogenophenyloxazoline. This step can be realize in several routes. One of them is onepot condensation of the 2-halogenobenzoic acid with the amino alcohol (Scheme 1, Method 1) [14]. Others are one-pot reaction of the amino alcohol with the 2-halogenobenzonitrile catalyzed with $\mathrm{ZnCl}_{2}$ (Scheme 1, Method 2) [15] and condensation with an imidate (Scheme 1, Method 3). The halogenophenyloxazolines are also synthesize in three steps synthesis (Scheme 2) involving formation of an amide, in the first step, and next transformation of the hydroxyl group into a leaving group $\mathrm{Cl}$ (Scheme 2, Method 4) or OTs (Scheme 2, Method 5) [16] followed by the ring closure or direct cyclization in presence of $\mathrm{Bu}_{2} \mathrm{SnCl}_{2}$ (Scheme 2, Method 6) [17]. 


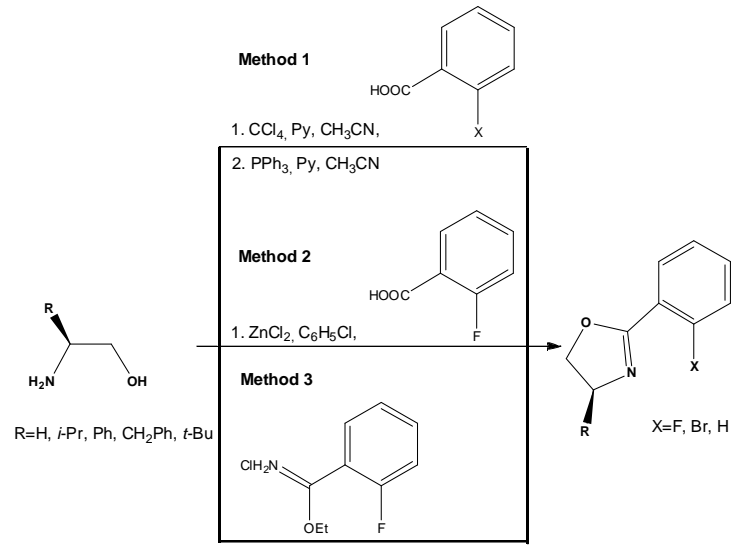

Scheme 1
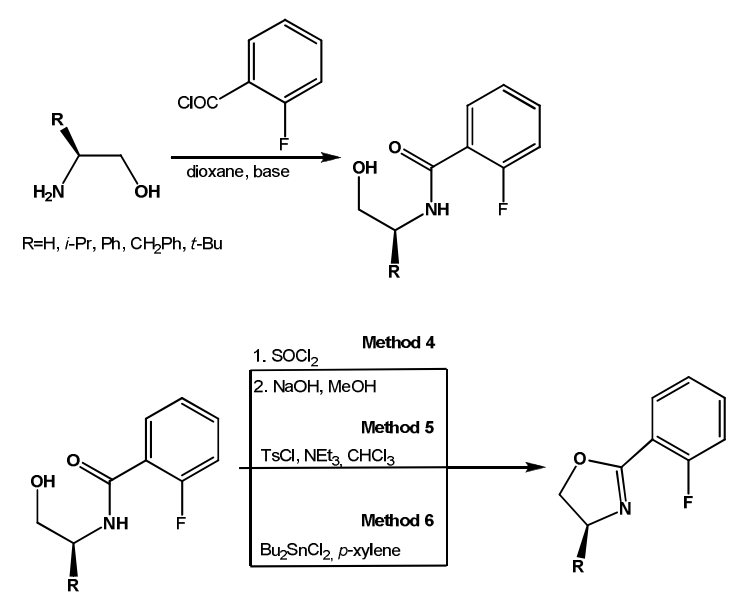

Scheme 2

The last step in the PHOX ligands construction is substitution of a halogen atom by the phosphino group (Scheme 3, Method 7 and 8). In Method 7 (nucleophilic substitution), fluoro substituted 2-phenyloxazoline is treated with $\mathrm{LiPPh}_{2}$ [18], whereas in Method 8 bromo-oxazoline is converted into an organomagnesium derivative followed by treatment with chloro-diphenylphosphine to give the phosphinooxazoline [19].

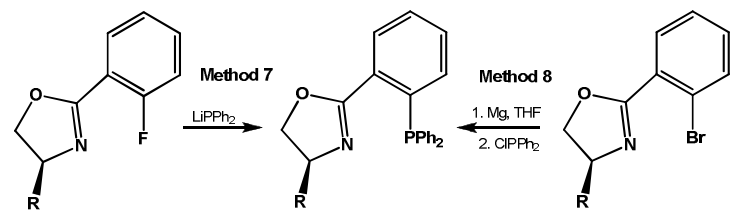

Scheme 3

Another approach to the synthesis of PHOX ligands commences from the 2-bromobenzonitrile, in which bromine atom is substituted by diphenylphosphine group in reaction with n-butyl lithium and chloro-diphenylphosphine. Next, 3 react with amino alcohols in the presence of zinc chloride to give air-stable $\mathrm{Zn}$ complexes 4, which by treatment with bipyridine provide pure PHOX ligands (Scheme 4) [1].
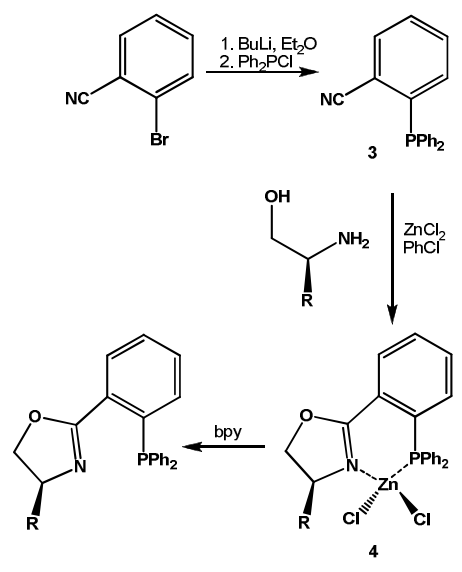

Scheme 4

\subsection{Application of PHOX ligands}

Transition metals such as iridium, rhodium, ruthenium and palladium are employed as metal centers in the catalytic reactions, in which PHOX ligands are used.

Cationic iridium (I) complexes of chiral PHOX ligands are used as catalysts for the enantiolesective hydrogenation of prochiral unfunctionalized trisubstituted olefins (Fig. 2, Table 1, Scheme 5, Table 2) [20] and $N$-alkyl or $N$-aryl imines (Fig. 3, Scheme 6, Table 3) [21]. The most popular and the most efficient anions in catalytic system are $\mathrm{PF}_{6}$ anion and BARF (tetrakis[3,5bis(trifluoromethyl)phenyl]borate. 
Table 1 Iridium (I) catalysts

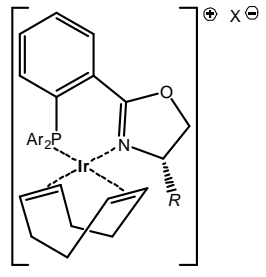

Fig. 2

\begin{tabular}{llll}
\hline Cat. & $\mathrm{Ar}$ & $\mathbf{R}$ & $\mathbf{X}$ \\
\hline $\mathbf{1}$ & $\mathrm{Ph}$ & $i-\mathrm{Pr}$ & $\mathrm{PF}_{6}$ \\
$\mathbf{2}$ & $\mathrm{Ph}$ & $t-\mathrm{Bu}$ & $\mathrm{PF}_{6}$ \\
$\mathbf{3}$ & $o-\mathrm{Tol}$ & $i-\mathrm{Pr}$ & $\mathrm{PF}_{6}$ \\
$\mathbf{4}$ & $o-\mathrm{Tol}$ & $t-\mathrm{Bu}$ & $\mathrm{PF}_{6}$ \\
$\mathbf{5}$ & $\mathrm{Ph}$ & $i-\mathrm{Pr}$ & $\mathrm{BARF}$
\end{tabular}

60 -Tol $t$-Bu BARF

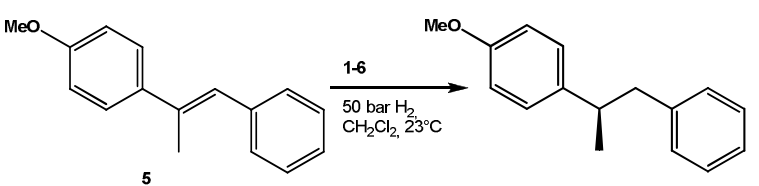

Scheme 5

Table 2 Enantioselective hydrogenation of 5 using iridium catalysts Cat. 1-6

\begin{tabular}{l|l|l}
\hline Cat. $(\mathrm{mol} \%)$ & Conversion [\%] & \%ee \\
\hline $\mathbf{1}(4)$ & 78 & 75 \\
$\mathbf{2}(4)$ & 98 & 90 \\
$\mathbf{3}(4)$ & $>99$ & 91 \\
$\mathbf{4}(4)$ & 57 & 97 \\
$\mathbf{5}(0,3)$ & $>99$ & 70 \\
$\mathbf{6}(0,3)$ & $>99$ & 98 \\
\hline
\end{tabular}

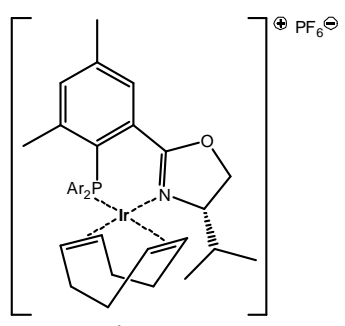

Fig. 3 Cat 7

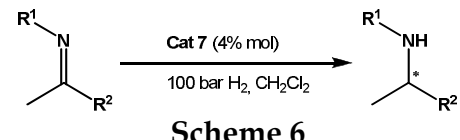

Table 3 Hydrogenation of imines catalyzed with Cat 7

\begin{tabular}{l|l|l|l|l}
\hline Entry & $\mathbf{R}^{\mathbf{1}}$ & $\mathbf{R}^{\mathbf{2}}$ & Conversion [\%] & $\%$ eee \\
\hline $\mathbf{1}$ & $\mathrm{Bn}$ & $\mathrm{Ph}$ & 100 & 76 \\
$\mathbf{2}$ & $\mathrm{Bn}$ & 2 -naphtyl & 100 & 69 \\
$\mathbf{3}$ & $\mathrm{Bn}$ & $\mathrm{Pr}$ & 30 & 9 \\
$\mathbf{4}$ & $\mathrm{Bn}$ & $\mathrm{C}_{6} \mathrm{H}_{11}$ & 100 & 20 \\
$\mathbf{5}$ & $\mathrm{Me}$ & $\mathrm{Ph}$ & 100 & 58 \\
$\mathbf{6}$ & $n \mathrm{Bu}$ & $\mathrm{Ph}$ & 100 & 75 \\
$\mathbf{7}$ & $\mathrm{Ph}$ & $\mathrm{Ph}$ & 100 & 71 \\
$\mathbf{8}$ & $\mathrm{Ph}$ & $n \mathrm{Pr}$ & 98 & 17 \\
\hline
\end{tabular}

Rhodium (I) complexes with PHOX ligands which are very good catalysts in asymmetric hydrosilylation of ketones. Hydrosililation is promoted by rhodium complexes and known to be tolerant to variety of functional groups in the substrates (Scheme 7, Fig. 4, Table 4) [22].

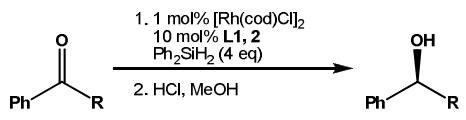

Scheme 7

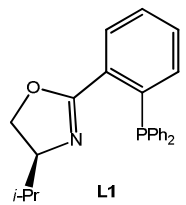<smiles>C[C@@H]1COC(c2ccccc2P)=N1</smiles>

Fig. 4

Table 4 Asymetric hydrosililation of ketones with phosphinooxazoline-rhodium (I) complexes

\begin{tabular}{llll}
\hline $\mathbf{R}$ & Ligand & Conversion [\%] & \%ee \\
\hline Me & L1 & 85 & 86 \\
Pr & L1 & 90 & 81 \\
Me & L2 & 77 & 51 \\
\hline
\end{tabular}

On the other hand, PHOX ligands form effective complexes with ruthenium for enantioselective transfer hydrogenation of 
ketones with isopropanol as a source of hydrogen. The complex $\left[\mathrm{RuCl}_{3}(\mathrm{L1}, 3,4)\left(\mathrm{PPh}_{3}\right)\right]$ promoted with $\mathrm{NaOH}$, showed exelent turnover in the reduction of alkyl phenyl ketones with isopropanol used in excess (Scheme 8, Fig. 5, Table 5) [11].

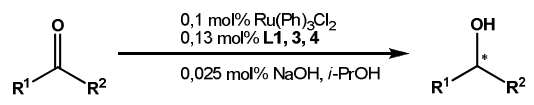

Scheme 8

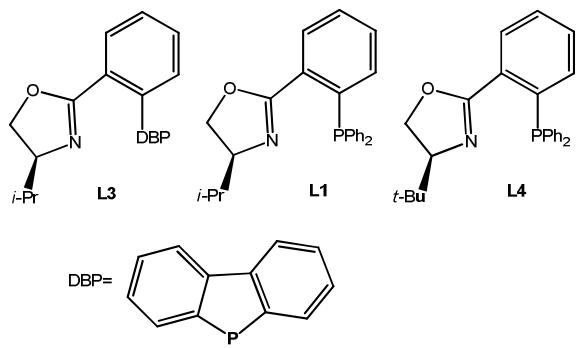

Fig. 5

Table 5 Enantioselective hydrogenation of ketones calatyzed by phosphinooxazoline-ruthenium complexes

\begin{tabular}{c|c|c|c|c|c}
\hline Entry & $\mathbf{R}^{\mathbf{1}}$ & $\mathbf{R}^{\mathbf{2}}$ & $\mathbf{L}$ & $\begin{array}{c}\text { Conversion } \\
{[\%]}\end{array}$ & $\begin{array}{c}\text { Ee } \\
{[\%]}\end{array}$ \\
\hline $\mathbf{1}$ & $\mathrm{Ph}$ & $\mathrm{Me}$ & 3 & 71 & 87 \\
$\mathbf{2}$ & $\mathrm{Ph}$ & $\mathrm{Me}$ & 1 & 24 & 94 \\
$\mathbf{3}$ & $\mathrm{Ph}$ & $\mathrm{Me}$ & 4 & 81 & 85 \\
$\mathbf{4}$ & $\mathrm{Ph}$ & $\mathrm{Et}$ & 3 & 50 & 91 \\
$\mathbf{5}$ & $\mathrm{Ph}$ & $i \mathrm{Pr}$ & 3 & 74 & 93 \\
$\mathbf{6}$ & cyclohexyl & $\mathrm{Me}$ & 3 & 70 & 60 \\
$\mathbf{7}$ & cyclohexyl & $\mathrm{Me}$ & 1 & 88 & 58 \\
\hline
\end{tabular}

\section{Results}

In continuation of our studies on the synthesis of terpene derived ligands, we decided to utilize amino alcohols obtained from $\beta$ - and $\alpha$-pinene to the synthesis of PHOX ligands. Followed the known procedure [23], (-)- $\beta$-pinene was transformed into amino alcohol 6, which reacted with 2- fluorobenzoyl chloride to give 2-fluoro- $N-((1 R, 2 S, 3 R, 5 R)-2$-hydroxy6,6-dimethyl bicyclo[3.1.1] heptan-3yl)benzamide 7 in $90 \%$ yield. 7 was then cyclized in the presence of dibutyltin dichloride in refluxing $p$-xylene to fluorophenyloxazoline $\mathbf{8}$ in $96 \%$ yield. Substitution of the fluorine atom by diphenylophosphino group led to final product 9 - PHOX ligand in 55\% yield (Scheme 9).
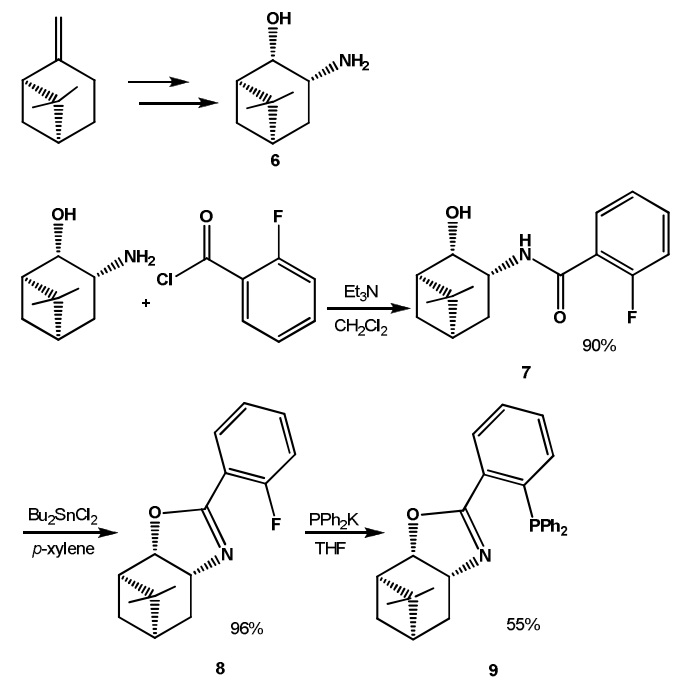

Scheme 9

Complexation of 9 with $\mathrm{RuCl}_{2}\left(\mathrm{PPh}_{3}\right)_{3}$ in isopropanol gave the solution of catalyst (Fig. 6) which was use in transfer hydrogenation of ketones (Scheme 10). We chose acetophenone as a model ketone to find the most efficient catalyst to substrate ratio. After several attemps the highest enantioselectivity in the reduction of acetophenone was obtained with $0,05 \% \mathrm{~mol}$ of Ru-9 catalyst (Table 6).

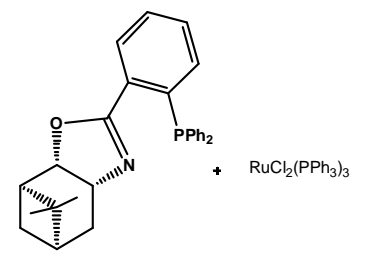

Fig. 6 


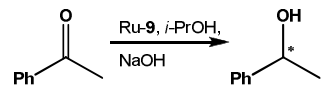

Scheme 10

Table 6 Transfer hydrogenation of acetophenone -the influence of catalyst amount

\begin{tabular}{ccc}
\hline \%mol Ru-9 & Yield [\%] & Ee [\%] \\
\hline 1 & 93 & 78 \\
0,5 & 98 & 75 \\
0,1 & 84 & 76 \\
0,075 & 84 & 80 \\
$\mathbf{0 , 0 5}$ & $\mathbf{9 8}$ & $\mathbf{9 0}$ \\
0,025 & 34 & 85 \\
0,001 & 3 & 71 \\
\hline
\end{tabular}

Next we determined the impact of the acetophenone concentration and the type of base on yield and enantioselectivity of the product alcohol (Table 7). We found that the concentration of ketone and the type of base play insignificant role in reaction, so we decided to make all reactions in $0,25 \mathrm{M}$ ketone solution.

Table 7 Influence of acetophenone concentration and type of base

\begin{tabular}{ccccc}
\hline \% mol Ru-9 & [ketone] & Base & Yield [\%] & Ee [\%] \\
\hline 0,05 & $0,25 \mathrm{M}$ & $\mathrm{NaOH}$ & 98 & 90 \\
0,05 & $0,25 \mathrm{M}$ & $t \mathrm{BuOK}$ & 87 & 90 \\
0,05 & $0,1 \mathrm{M}$ & $\mathrm{NaOH}$ & 98 & 83 \\
0,05 & $0,1 \mathrm{M}$ & $t \mathrm{BuOK}$ & 94 & 91 \\
\hline
\end{tabular}

After those preliminary studies, we started reduce others ketones: aryl-alkyl, aryl-aryl and alkyl-alkyl. Transfer hydrogenation reactions were conducted using $0,05 \%$ mol Ru-9 catalyst, $\mathrm{NaOH}$ or $t$ $\mathrm{BuOK}$ as a base in isopropanol solution with 0,25M ketone concentration (Table 8).
Table 8 Transfer hydrogenation of ketones wiht Ru-9 as catalyst

\begin{tabular}{|c|c|c|c|}
\hline Ketone & Base & Yield [\%] & $\operatorname{Ee}[\%]$ \\
\hline & $\mathrm{NaOH}$ & 98 & 90 \\
\hline & $t \mathrm{BuOK}$ & 99 & 90 \\
\hline & $\mathrm{NaOH}$ & 88 & 90 \\
\hline & $t \mathrm{BuOK}$ & 89 & 93 \\
\hline & $\mathrm{NaOH}$ & $68^{*}$ & $81^{*}$ \\
\hline & $t \mathrm{BuOK}$ & - & - \\
\hline & $\mathrm{NaOH}$ & 68 & 8 \\
\hline & $t \mathrm{BuOK}$ & 70 & $X x$ \\
\hline & $\mathrm{NaOH}$ & 99 & 82 \\
\hline & $t \mathrm{BuOK}$ & 57 & 87 \\
\hline & $\mathrm{NaOH}$ & 35 & 75 \\
\hline & $t \mathrm{BuOK}$ & 63 & 89 \\
\hline & $\mathrm{NaOH}$ & 66 & 81 \\
\hline & $t \mathrm{BuOK}$ & 99 & 77 \\
\hline & $\mathrm{NaOH}$ & \multicolumn{2}{|c|}{ No reduction } \\
\hline & $t \mathrm{BuOK}$ & - & - \\
\hline & $\mathrm{NaOH}$ & 88 & Rac \\
\hline & $t \mathrm{BuOK}$ & - & - \\
\hline & $\mathrm{NaOH}$ & 97 & 78 \\
\hline & $t \mathrm{BuOK}$ & 96 & 87 \\
\hline & $\mathrm{NaOH}$ & 53 & 79 \\
\hline & $t \mathrm{BuOK}$ & 67 & 87 \\
\hline & $\mathrm{NaOH}$ & 95 & 85 \\
\hline & $t \mathrm{BuOK}$ & 96 & 83 \\
\hline & $\mathrm{NaOH}$ & 39 & 82 \\
\hline & $t \mathrm{BuOK}$ & 45 & 82 \\
\hline
\end{tabular}




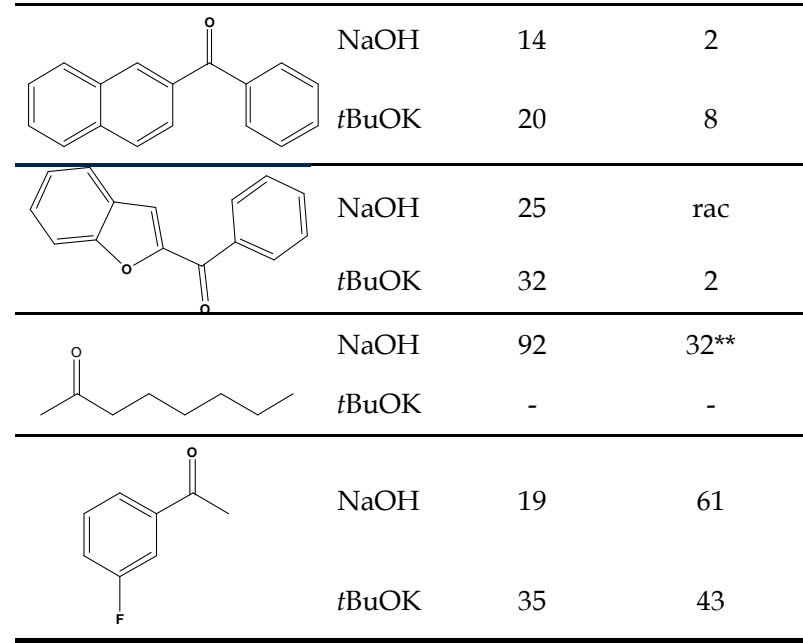

*-for 2-phenyloxirane, ${ }^{* *}$-for $p$-nitrophenyl derivative

In extension to our studies we decided to examine the influence of monoterpene structure on enantioselectivity of the reduction. We commenced our new PHOX ligand synthesis from (-)-a-pinene which was transformed to the appropriate amino alcohol 10 [24] in few steps. Then $\mathbf{1 0}$ was converted to amide $\mathbf{1 1}$ in reaction with 2-bromobenzoyl chloride in $64 \%$ yield. Cyclization of $\mathbf{1 1}$ in the presence of dibutyltin dichloride led to bromophenyl oxazoline 12 in $62 \%$ yield. In the last step of the ligand synthesis, bromo-oxazoline $\mathbf{1 2}$ was treated wint $n$-butyl lithium followed by the reaction with chlorodiphenyl phosphine to give PHOX ligand 13 in 63\% yield (Scheme 11).

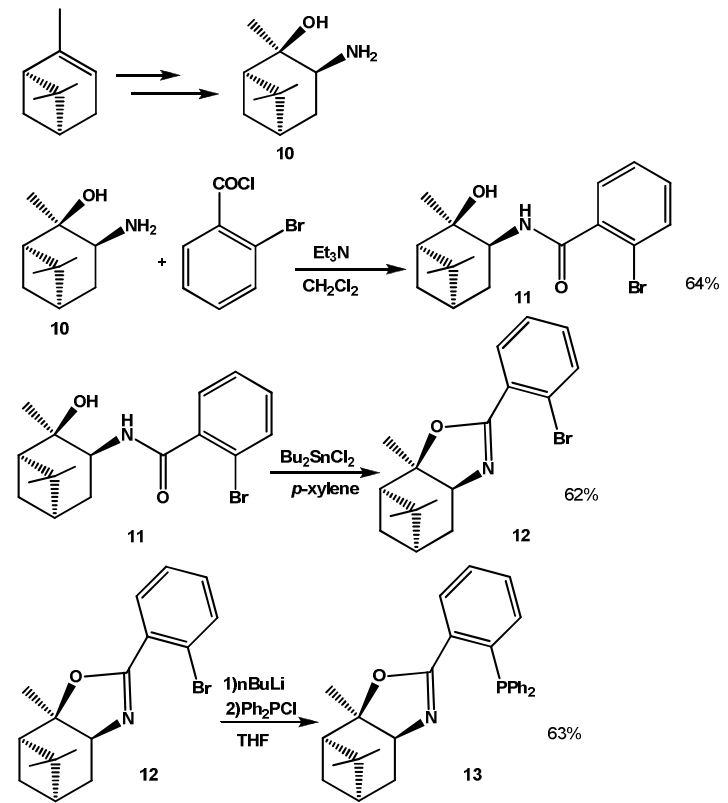

Scheme 11

Ligand 13 combined with $\mathrm{RuCl}_{2}\left(\mathrm{PPh}_{3}\right)_{3}$ in isopropanol gave catalyst solution Ru-13 (Fig. 7) which was used in transfer hydrogenation of ketones (Table 9).

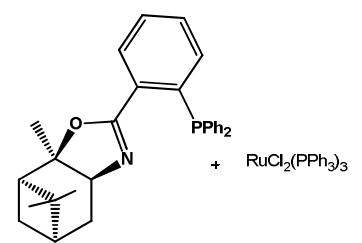

Fig. 7

Table 9 Transfer hydrogenation of ketones wiht Ru-13 as catalyst

\begin{tabular}{|c|c|c|c|c|}
\hline Ketone & $\begin{array}{c}\text { \% mol } \\
\text { Ru-13 }\end{array}$ & Base & Yield [\%] & $\begin{array}{c}\text { Ee } \\
{[\%]}\end{array}$ \\
\hline & 0,05 & & 27 & 24 \\
\hline & 0,1 & $\mathrm{NaOH}$ & 72 & 37 \\
\hline & 0,5 & & 66 & 36 \\
\hline & 0,1 & $\mathrm{NaOH}$ & 93 & 51 \\
\hline & 0,1 & $\mathrm{NaOH}$ & 53 & 10 \\
\hline
\end{tabular}




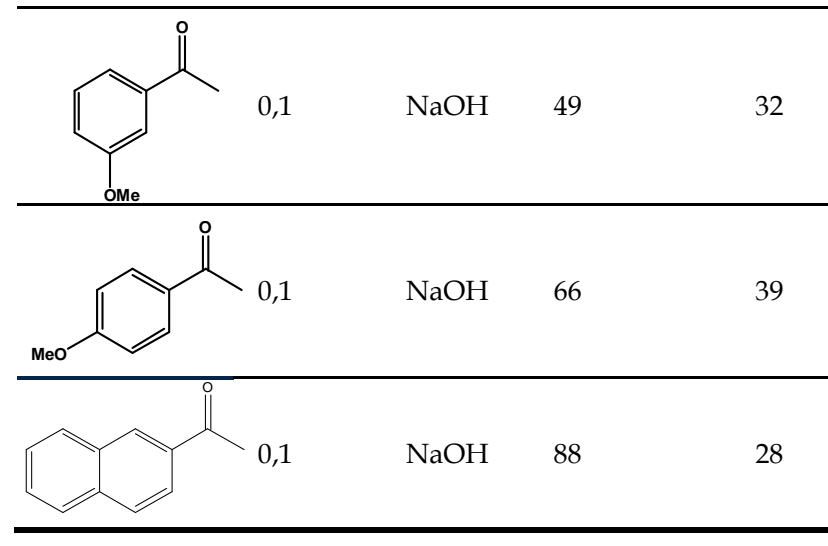

\section{Conclusion}

Catalyst Ru-9 gives much better results in asymmetric transfer hydrogenation of ketones than Ru-13. Reductions proceed with higher yields and higher enanciomeric excesses. We can use twice fewer amount of the catalyst in reduction with $\mathbf{R u}-\mathbf{9}$ compared to $\mathbf{R u - 1 3}$. The lower reactivity and enantioselectivity of $\mathbf{R u - 1 3}$ may be a consequence of the trans position of the oxazoline ring to the gem-dimethyl bridge in pinane ring system.

\section{References}

[1] G.Helmchen, A.Pfaltz, Acc. Chem. Res. 2000, 33, 336.

[2] P.von Matt, A.Pfaltz, Angew. Chem., Int. Ed. Engl. 1993, 32,566.

[3] J.Sprinz, G.Helmchen, Tetrahedrn Lett., 1993, 34, 1769.

[4] G.J.Dawson, C.G.Frost, J.M.Williams, S.J.Coote, Teyrahedron Lett., 1993, 34,3149.

[5] R.Crabtree, Acc. Chem. Res., 1979, 12, 331.

[6] F.M.Geisler, G.Helmchen, J. Org. Chem., 2006, 71, 2486.

[7] J.A.Keith, D.C.Behenna, J.T.Mohr, S.Ma, S.C.Marinescu, J.Oxgaard, B.M. Stoltz, W.A.Goddard III, J. Am. Chem. Soc., 2007, 129, 11876.

[8] O. Loiseleur, M. Hayashi, M.Keenan, N.Schmees, A.Pfaltz, J. Organomet. Chem., 1999, 576, 16.

[9] a) S.Bell, B.Wüstenberg, S.Kaiser, F.Menges, T.Netscher, A.Pfaltz, Science, 2006, 311, 642.

b) D.Liu, W.Tang, X.Zhang, Org. Lett., 2004, 6, 513.

[10] F.Naud, C. Malan, F.Spindler, C. Rüggeberg, A.T.Schmidt, H.U.Blaser, Adv. Synth. Catal., 2006, 311, 47.

[11] T.Langer, G.Helmchen, Tetrahedron Lett., 1996, 37, 1381.

[12] D.Ca, C.Vega, N.Garcia, F.J.Lahoz, S.Elipe, L.A.Oro, M.P.Lamata, F.Viguri, F.Viguri, R.Borao, Organometallics, 2002, 21, 1841.
[13] E.L.Stangeland, T.Sammakia, Tetrahedron, 1997, 53, 16503.

[14] H.Vorbrüggen, K.Krolikiewicz, Tetrahedron, 1993, 49, 9353.

[15] H.Witte, W.Seeliger, Liebigs Ann. Chem., 1974, 996.

[16] C.Giordano, S.Cavicchioli, S.Levi, M.Villa, Tetrahedron Lett., 1988, 29, 5561.

[17] S.Masamune at all, United States Patent 5,298,623, 1994.

[18] J.V.Allen, G.J.Dawson, C.G.Frost, J.M.J.Williams, Tetrahedron, 1994, 50, 799.

[19] J.M.Brown, V.K.Baker, N.Hughs, A.J.Skarnulis, A.Sexton, J. Org. Chem., 1991, 56, 698.

[20] A.Lightfoot, P.Schnider, A.Pfaltz, Angew. Chem. Int. Ed., 1998, 37, 2897.

[21] P.Schnider, G.Koch, R.Prétôt, G.Wang, F.M.Bohnen, C.Krüger, A.Pfaltz, Chem. Eur. J., 1997, 6, 887.

[22] L.M.Newman, J.M.J.Williams, R.McCague, G.J.Potter, Tetrahedron Asymetry, 1996, 6, 1597.

[23] M.P.Krzemiński, A.Wojtczak, Tetrahedron Lett., 2005, 46, 8299.

[24] M.Masui, T.Shioiri, Tetrahedron, 1995, 51, 8363. 